Volume 8

Issue 4 - Cancer Screening

Article 1

$10-18-2021$

\title{
Refining a Postpandemic Approach to Cancer Screening
}

Michael A. Thompson

Follow this and additional works at: https://aah.org/jpcrr

Part of the Community Health and Preventive Medicine Commons, Health Services Research

Commons, Investigative Techniques Commons, Neoplasms Commons, Oncology Commons, Preventive Medicine Commons, Primary Care Commons, and the Women's Health Commons

\section{Recommended Citation}

Thompson MA. Refining a postpandemic approach to cancer screening. J Patient Cent Res Rev. 2021;8:295-6. doi: 10.17294/2330-0698.1913

Published quarterly by Midwest-based health system Advocate Aurora Health and indexed in PubMed Central, the Journal of Patient-Centered Research and Reviews (JPCRR) is an open access, peer-reviewed medical journal focused on disseminating scholarly works devoted to improving patient-centered care practices, health outcomes, and the patient experience. 


\title{
Refining a Postpandemic Approach to Cancer Screening
}

\author{
Michael A. Thompson, MD, PhD | Special Issue Editor (Cancer Screening) \\ Aurora Cancer Care, Advocate Aurora Health, Milwaukee, WI; Advocate Aurora Research Institute, Milwaukee, WI
}

$\mathrm{T}$ The purpose of cancer screening is early detection, which hopefully leads to early cancer prevention/ treatment, curability, or at least risk reduction. Cancer screening may be defined as a comprehensive approach to risk stratification that includes patient history, physical examination, social and family history, and recommended testing. Often, however, cancer screening refers to a single modality such as mammography (and newer imaging systems) or colonoscopy (and various stool sample testing options). More sophisticated methods to potentially evaluate screening for multiple cancers using molecular platforms are currently being researched. ${ }^{1}$ Examples include the Galleri ${ }^{\mathrm{TM}}$ assay (GRAIL, now part of Illumina, Inc.), for which the United Kingdom's National Health Services launched a clinical trial targeting 140,000 volunteers in September 2021, and CancerSEEK (Exact Sciences Thrive LLC). ${ }^{2-4}$

While continuous advances in cancer screening techniques keep the industry and health care providers on their toes, contemporary practices generally rely on a few staples. We know that ascertaining an accurate family history can identify potential genetic predispositions to cancer. However, in time- and resource-constrained clinical offices, the status of family history collection, documentation, and actionability often are not optimal. ${ }^{5}$ Genetic counseling referrals are encouraged but may be underutilized for a variety of reasons, including access (location and cost) and genetic counselor availability in some health systems. ${ }^{5}$ Approaches are needed to increase the supply of genetic counselors in number and access. This may include increased training programs, telegenetics, and algorithm-assisted identification of patients for increased genetic assessment. ${ }^{6,7}$

We also know that frequency of cancer screening depends in part on access to health care. During the COVID-19 pandemic, the Centers for Disease Control and Prevention reported $80 \%$ declines in screenings for breast and

Corresponding author: Michael A. Thompson, Vince Lombardi Cancer Clinic, 2900 W. Oklahoma Ave., Milwaukee, WI 53215 (Michael.Thompson2@aah.org) cervical cancer. ${ }^{8,9}$ Unger and colleagues showed that there was a "... precipitous decrease in enrollments during the initial COVID-19 wave, but only a modest reduction during the winter 2020-2021 wave. ${ }^{10}$ Over the entire year, steep enrollment reductions were found for cancer control and prevention trials, whereas for treatment trials,

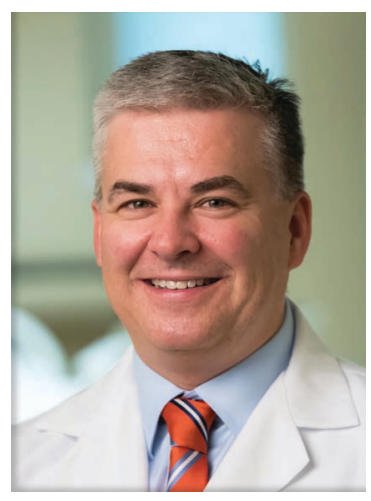
enrollments were similar to expected rates." The authors further noted that "these findings suggest that clinical trial research rapidly adapted to the circumstances of enrolling and treating patients on protocols during the COVID-19 pandemic." ${ }^{10}$ Future studies will further examine screening trends in the pandemic's aftermath (recognizing that end is currently not defined). There have been calls for "applying a pandemic-like response to cancer prevention." could include utilizing personalization (as with precision medicine) or artificial intelligence. ${ }^{12}$

While some screening methods have not been useful eg, chest X-ray for lung cancer ${ }^{13}$ or CA125 testing for ovarian cancer ${ }^{14}$ — others have been tested rigorously and been found to have utility, such as computed tomography lung cancer screening in specific populations. ${ }^{15,16}$

In this theme issue of the Journal of Patient-Centered Research and Reviews (JPCRR), multiple articles delve into a range of cancer prevention topics. Brady et al qualitatively evaluated barriers to and promoters of cancer screening. ${ }^{17}$ The same authorship group implemented quality improvement strategies over 7 years in an effort to increase cancer screening rates in safety-net primary care practices. ${ }^{18}$ In a pair of research studies, Saman et al gleaned patient perceptions of clinical decision support tools targeting cancer prevention, ${ }^{19}$ while Schrager et al evaluated the effect of shared decision-making and other patient and clinician characteristics on breast cancer screening rates for women in their $40 \mathrm{~s} .{ }^{20} \mathrm{Schad}$ et al reported the negative, but variable, impact of the COVID-19 pandemic on breast, cervical, and colorectal cancer screening rates in primary care settings, ${ }^{21}$ and El 
Khoury et al researched patients' potential willingness to overcome some of this disruption through expanded utilization of home-based screening tests for colorectal cancer and cervical cancer. ${ }^{22}$ Among the remaining articles published within this issue of JPCRR, a topic synopsis on genetic testing for familial hypercholesterolemia shares insights that could also be applied to improving testing for genetic risk in the cancer setting. ${ }^{23}$

There remains much to be learned about how we can best use screening measures, both old and new, to detect malignancies as early as possible without unnecessarily wasting valuable time and resources. The works reported herein add to the ongoing discussions around how to prevent and control cancer for maximal patient benefit while improving the cost of cancer care both in "normal" times and in the context of a pandemic.

\section{Conflicts of Interest}

Dr. Thompson served on an advisory board for GRAIL/Illumina, manufacturer of the investigative Galleri ${ }^{\mathrm{TM}}$ multicancer assay.

\section{References}

1. May M. Catching cancer extremely early. Science. 2021 Mar 26. Accessed September 13, 2021. https://www.science.org/ features/2021/03/catching-cancer-extremely-early

2. Beer TM, McDonnell $\mathrm{CH}$, Nadauld $\mathrm{L}$, et al. Interim results of PATHFINDER, a clinical use study using a methylationbased multi-cancer early detection test. (abstr.) J Clin Oncol. 2021;39(suppl 15):3010. CrossRef

3. Beer TM, McDonnell CH, Nadauld L, et al. A prespecified interim analysis of the PATHFINDER study: Performance of a multicancer early detection test in support of clinical implementation. (abstr.) J Clin Oncol. 2021;39(suppl 15):3070. CrossRef

4. Cohen JD, Li L, Wang Y, et al. Detection and localization of surgically resectable cancers with a multi-analyte blood test. Science. 2018;359:926-30. CrossRef

5. Taber P, Ghani P, Schiffman JD, et al. Physicians' strategies for using family history data: having the data is not the same as using the data. JAMIA Open. 2020;3:378-85. CrossRef

6. Hanson K, Mullane M, Schnettler E, et al. Identification of potential germline (GL) variants by routine clinical comprehensive genomic profiling (CGP) and confirmatory GL testing in 24 tumor types. (abstr.) J Clin Oncol. 2021;39(suppl 15):10596. CrossRef

7. Stadler ZK, Malo A, Chakravarty D, et al. Therapeutic implications of germline testing in patients with advanced cancers. J Clin Oncol. 2021;39:2698-709. CrossRef

8. Byrne J. CDC reports $80 \%$ declines in breast, cervical cancer screenings during start of pandemic. HemOnc Today. 2021 Jun 30. Accessed September 13, 2021. https://www.healio.com/ news/hematology-oncology/20210630/cdc-reports-80-declinesin-breast-cervical-cancer-screenings-during-start-of-pandemic

9. DeGroff A, Miller J, Sharma K, et al. COVID-19 impact on screening test volume through the National Breast and Cervical Cancer early detection program, January-June 2020, in the United States. Prev Med. 2021;151:106559. CrossRef
10. Unger JM, Xiao H, LeBlanc M, Hershman DL, Blanke CD. Cancer clinical trial participation at the 1-year anniversary of the outbreak of the COVID-19 pandemic. JAMA Netw Open. 2021;4(7):e2118433. CrossRef

11. Castle PE. Applying a pandemic-like response to cancer prevention. STAT. 2021 Aug 9. Accessed September 13, 2021. https://www.statnews.com/2021/08/09/applying-a-pandemiclike-response-to-cancer-prevention/

12. Khozin S [@SeanKhozin]. Cancer interception/prevention among most viable strategies to tame emperor of all maladies in 21 st century, possibly curing deadliest malignancies. \#AI/diagnostics critical tools. Twitter communication. Posted August 9, 2021. https://twitter.com/SeanKhozin/ status/1424816135875137545?s=20

13. Fontana RS, Sanderson DR, Woolner LB, Taylor WF, Miller WE, Muhm JR. Lung cancer screening: the Mayo program. J Occup Med. 1986;28:746-50. CrossRef

14. Henderson JT, Webber EM, Sawaya GF. Screening for ovarian cancer: updated evidence report and systematic review for the US Preventive Services Task Force. JAMA. 2018;319:595-606. CrossRef

15. National Lung Screening Trial Research Team; Aberle DR, Adams AM, Berg CD, et al. Reduced lung-cancer mortality with low-dose computed tomographic screening. $N$ Engl $J$ Med. 2011;365:395-409. CrossRef

16. Jonas DE, Reuland DS, Reddy SM, et al. Screening for lung cancer with low-dose computed tomography: updated evidence report and systematic review for the US Preventive Services Task Force. JAMA. 2021;325:971-87. CrossRef

17. Brady LA, Tumiel-Berhalter LM, Schad LA, et al. Increasing breast, cervical, and colorectal cancer screenings: qualitative assessment of barriers and promoters in safety-net practices. J Patient Cent Res Rev. 2021;8:323-30.

18. Morley CP, Schad LA, Tumiel-Berhalter LM, et al. Improving cancer screening rates in primary care practices via practice facilitation and academic detailing: a multi-PBRN quality improvement project. J Patient Cent Res Rev. 2021;8:315-22.

19. Saman DM, Harry ML, Freitag LA, et al. Patient perceptions of using clinical decision support for cancer screening and prevention: "I wouldn't have thought about getting screened without it." J Patient Cent Res Rev. 2021;8:297-306.

20. Schrager S, Evaristo C, Little T, DuBenske L, Burnside B. Patient and clinician characteristics that predict breast cancer screening behavior in 40-49-year-old women. J Patient Cent Res Rev. 2021;8:331-5.

21. Schad LA, Brady LA, Tumiel-Berhalter LM, et al. Impact of COVID-19 on screening rates for colorectal, breast and cervical cancer: practice feedback from a quality improvement project in primary care. J Patient Cent Res Rev. 2021;8:347-53.

22. El-Khoury C, Haro E, Alves M, et al. Patient-centered home cancer screening attitudes during COVID-19 pandemic. J Patient Cent Res Rev. 2021;8:340-6.

23. Hendricks-Sturrup R, Block R, Lu CY. Integrating patientreported outcomes into clinical genetic testing for familial hypercholesterolemia. J Patient Cent Res Rev. 2021;8:336-9.

(C) 2021 Advocate Aurora Health, Inc. 